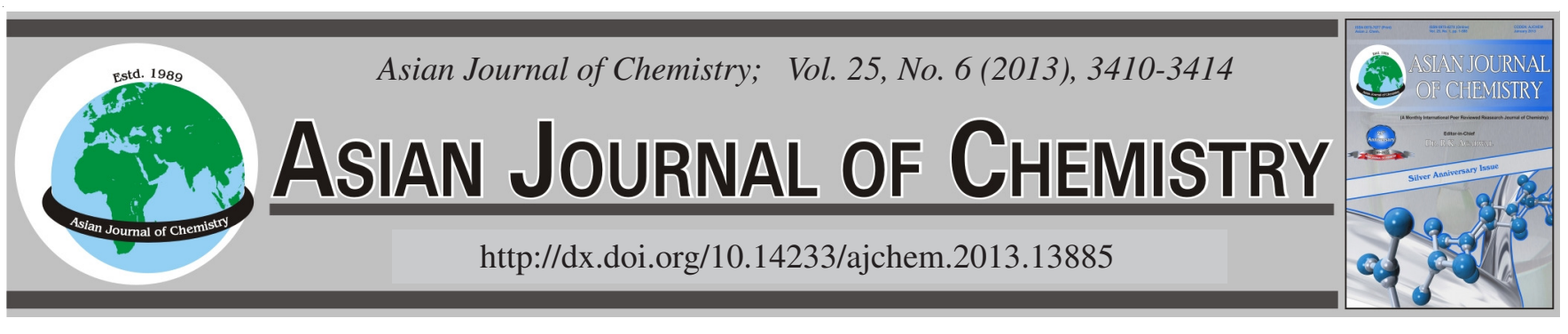

\title{
Colourimetric Estimation of Escitalopram Oxalate in Formulation by Ion Association Complex with Methyl Orange
}

\author{
Pushraraj Hemalatha ${ }^{1,2}$, Mani Ganesh ${ }^{1,2}$, Mei Mei Peng ${ }^{1,2}$ and Hyun Tae Jang ${ }^{1,2, *}$
}

${ }^{1}$ Department of Chemical Engineering, Hanseo University, 360 Daegok-ri, Haemi-myun, Seosan-si 356 706, Chungcheongnam-do, South Korea ${ }^{2}$ Korea Carbon Capture and Sequestration R and D Centre, 360 Daegok-ri, Haemi-myun, Seosan-si 356 706, Chungcheongnam-do, South Korea

*Corresponding author: E-mail: htjang@hanseo.ac.kr

\begin{abstract}
A new and fully validated ion pair spectrophotometric method has been developed for estimation for escitalopram oxalate in bulk and tablet formulation using acidic methyl orange dye as an ion associating agent in the absence of buffer. The developed method is sensitive and specific for the intended purpose of estimation. Ion association complex of escitalopram oxalate and methyl orange obeys Beer's law in the range of 4-24 $\mu \mathrm{g} \mathrm{mL}^{-1}$ of escitalopram oxalate with a correlation coefficient of 0.9987 . Accuracy, precision, stability, LOD, LOQ, interference, robustness and ruggedness were studied for validation of the method. The results recovery with low \% RSD of $0.88-1.02$; precision is also good in agreement with validation limits. The method developed was successfully applied for the estimation of the escitalopram oxalate in its formulation.
\end{abstract}

Key Words: Escitalopram, Methyl orange, Ion association, Spectrophotometric.

\section{INTRODUCTION}

Escitalopram oxalate is highly active $\mathrm{S}(+)$-enantiomers of citalopram, chemically $\mathrm{S}(+)-1-[3-($ dimethyl-amino) propyl]1-( $p$-fluorophenyl)-5-phthalancarbonitrile (Fig. 1) ${ }^{1}$. Escitalopram oxalate is an orally administered selective serotonin reuptake inhibitor prescribed for treating depression, panic, premenstrual dysphoric and obsessive-compulsive disorder ${ }^{2,3}$. Escitalopram oxalate is the active moiety of citalopram responsible for the antidepressant effect, it is two times more potent than citalopram and 40 times more than R-citalopram. Escitalopram oxalate blocks the reuptake of serotonin at the serotonin reuptake pump of the neuronal membrane $e^{4-7}$.<smiles>CN(C)CCCC1(c2ccc(F)cc2)OCc2cc(C#N)ccc21</smiles>

Fig. 1. Structure of escitalopram oxalate

Escitalopram oxalate is official in Merck index but not official in any pharmacopoeias ${ }^{8}$. Several methods have been reported earlier for the estimation of escitalopram oxalate in biological matrix by $\mathrm{LC} / \mathrm{MS} / \mathrm{MS}^{9-11}$ and in pharmaceuticals either with citalopram (R-enantiomer) or with clonazepam in combined formulation by column-switching high performance liquid chromatography ${ }^{12}$, chiral liquid chromatography for enanitomeric separation of escitalopram oxalate and citalopram $^{13}$, capillary electrophoresis ${ }^{14}$, HPLC-UV detection $^{15,16}$, HPTLC ${ }^{17}$, UV spectrophotometric ${ }^{18-21}$, colourimetric estimation using bromate-bromide complexation ${ }^{22}$ and by extractive colourimetric estimation using bromocresol green at $\mathrm{pH} 3$ phthalate buffer ${ }^{23}$. The later ion pair colourimetric method reported was partially validated for its suitability. As the $\mathrm{pH}$ of drug solution was 3.5, addition of buffer is not a necessity. In recent past, extractive colourimetric method has attracted researchers due to their ease and versatility. Hence, in the present study a simple, precise, accurate and validated extractive colourimetric method for the estimation of escitalopram oxalate using methyl orange as an ion paring agent in the absence of buffer was developed.

\section{EXPERIMENTAL}

All chemicals of analytical reagent grade were procured from Daejung Chemicals and Metals. Doubly distilled water was used to prepare all solutions. Freshly prepared solutions were used for method development and validation. Methyl orange of concentration $0.05 \% \mathrm{w} / \mathrm{v}$ was prepared using 
ethanol-water (1:9). Standard escitalopram oxalate was obtained from Sigma Aldrich and tablets containing $60 \mathrm{mg}$ active material were purchased from a retail pharmacy.

A Shimadzu UV mini-1240 UV-visible spectrophotometer (Japan) with $1 \mathrm{~cm}$ quartz cells was used for all spectral measurements with Shimadzu UV Probe (version 2.1) system software. The $\mathrm{pH}$ measurements were carried out using a calibrated digital $\mathrm{pH}$ meter (Neomet).

Standard solution of the drug: $1 \mathrm{mg} \mathrm{mL}^{-1}$ escitalopram oxalate standard stock solution was prepared by dissolving accurately weighed quantity of the drug in water. Working standards were prepared by suitable serial dilution.

Sample preparation: Aliquots were transferred from the $100 \mu \mathrm{g} \mathrm{mL}^{-1}$ working standard solution into a series of 100 $\mathrm{mL}$ separating funnels. To each this funnel $0.5 \mathrm{~mL}$ of $0.05 \%$ $\mathrm{w} / \mathrm{v}$ methyl orange was added and shaken well to make complex. The complex was extracted using $10 \mathrm{~mL}$ of chloroform. The extracted chloroform layer was passed through a funnel containing previously dried anhydrous sodium sulphate (approximately $2 \mathrm{~g}$ ) to remove the water in the organic layer in order to avoid the interference of the same during estimation.

General procedure for formulations: Twenty tablets from the marketed formulation were weighed and average weight of each tablet was calculated and grounded to fine powder. From the mixture a known quantity of powder required for dilution was accurately weighed and transferred into a $50 \mathrm{~mL}$ volumetric flask. The volume was made up to the mark with water, shaken well and the insoluble ingredients were filtered through a Whatman filter paper No. 40. Convenient aliquots of this solution were taken for the assay of escitalopram oxalate.

\section{RESULTS AND DISCUSSION}

Methyl orange an anionic dye forms an ion-association complex with the cationic nitrogen in escitalopram oxalate. The drug-dye stoichiometric ratio was calculated by the Job's continuous variation method and it was found that the escitalopram oxalate and methyl orange forms a 1:4 complex ${ }^{24}$. The formed escitalopram oxalate-methyl orange complex is a pair of two oppositely charged ions held together by an electrostatic force of attraction ions, acting as a single unit (Fig. 2).

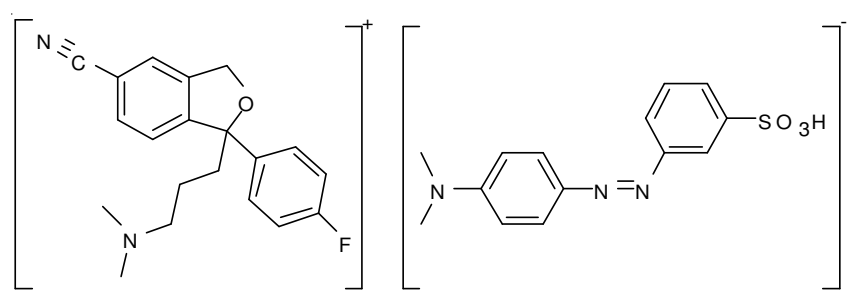

Fig. 2. Structure of escitalopram oxalate-methyl orange ion-pair complex

Maximum absorbance $\left(\boldsymbol{\lambda}_{\max }\right)$ measurement: Absorption spectrum of the yellow escitalopram oxalate-methyl orange ionpair complex was obtained by scanning the chloroform extracted chromogen from 350-600 nm. The results are depicted in Fig. 3(a). A maximum absorbance $\left(\lambda_{\max }\right)$ was noted at $422 \mathrm{~nm}$ and the same is used for further studies of estimation.
Validation of the method: Method optimization was carried out for the routine malleability of the method by a number of preliminary experiments for rapid and quantitative formation of coloured ion-pair complexes. The $\mathrm{USP}^{25}$ and $\mathrm{ICH}^{26}$ guidelines were followed for method validation. As the escitalopram solution itself is acidic, it readily forms complex with ion-pairing agent, methyl orange. Hence, further addition of acidic buffer is not a required criterion. From various trials on solvent suitability, chloroform was chosen as better choice of solvent for extraction among carbon tetrachloride, dichloromethane and diethyl ether. The suitability chloroform for extraction of ion-pair is also supported by other researchers $^{23}$.

Linearity and range: Beer's law limit, molar absorptivity and $\lambda_{\max }$ were determined and the results are given in Fig. 3(b) and Table-1. To determine the Beer's law limit, a calibration curve was constructed by plotting the absorbance against concentrations $(\mu \mathrm{g} / \mathrm{mL})$. The regression equation for the results was:

$$
A=0.0472 x-0.1622(r=0.9987)
$$

where, A, the absorbance at $422 \mathrm{~nm}, \mathrm{x}$, concentration of escitalopram oxalate in $\mu \mathrm{g} \mathrm{mL} \mathrm{m}^{-1}$ and $\mathrm{r}$, correlation coefficient.
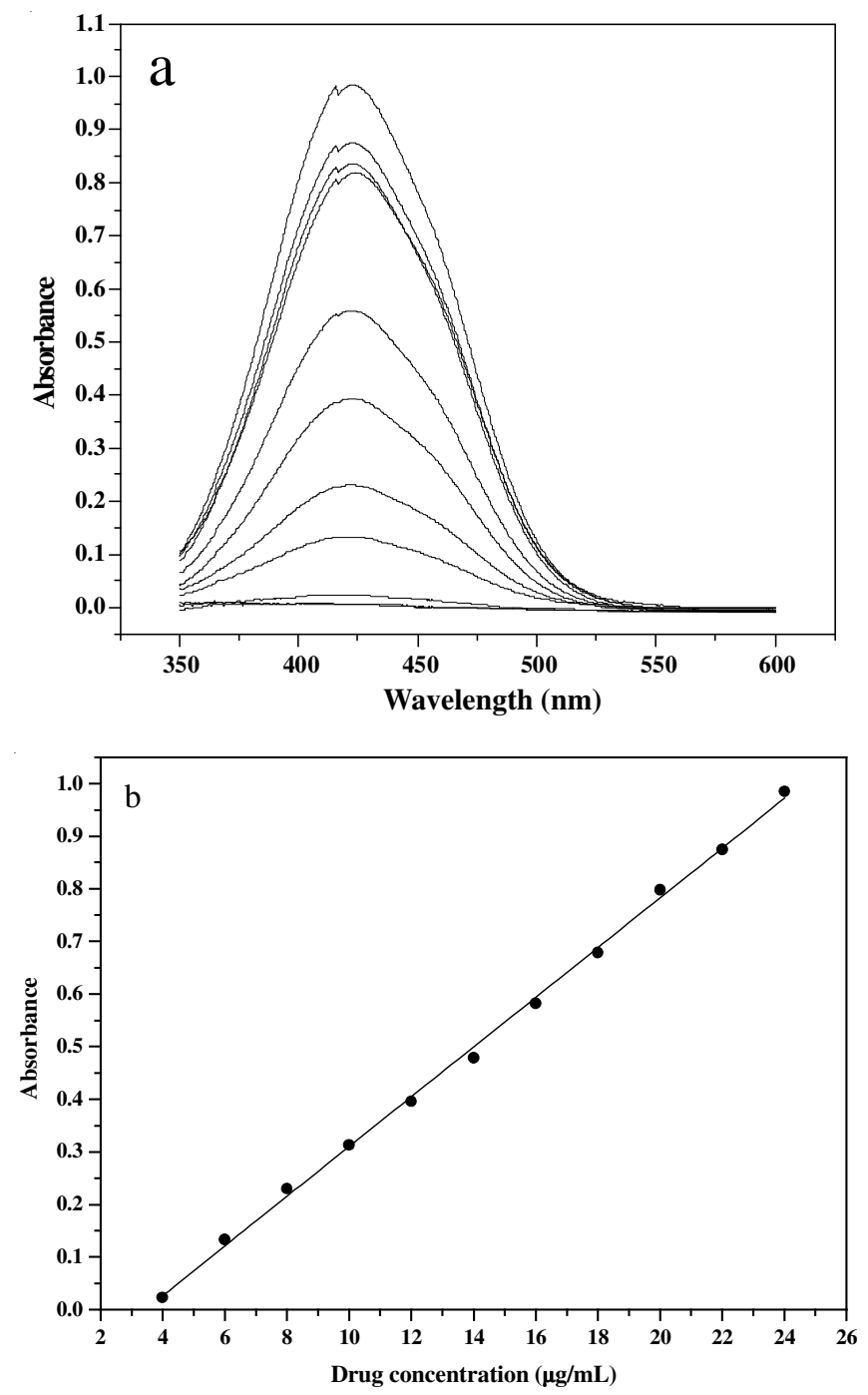

Fig. 3. (a) Overlay absorption spectra of escitalopram oxalate-methyl orange ion-pair complex; (b) Beer's law standard plot 


\begin{tabular}{|c|c|}
\hline \multirow{2}{*}{ Label claim (mg/tab) } & $\operatorname{Amount}^{\mathrm{a}}(\%)$ \\
\hline & Reported \\
\hline 60 & 100.01 \\
\hline \multicolumn{2}{|c|}{${ }^{\mathrm{a}}$ Mean of six determinations; ${ }^{\mathrm{b}}$ The tabulated values of $t$ and $F$ at $95 \% \mathrm{c}$} \\
\hline \multicolumn{2}{|c|}{$\begin{array}{l}\text { The molar absorptivity }(\varepsilon) \text { was found to be } 1.2971 \times 10^{4} \mathrm{~L} \\
\mathrm{~mol}^{-1} \mathrm{~cm}^{-1} \text {. The Sandell's sensitivity was also determined and } \\
\text { presented in the same table. }\end{array}$} \\
\hline \multicolumn{2}{|c|}{$\begin{array}{c}\text { TABLE-1 } \\
\text { OPTICAL PROPERTY OF THE CHROMOGEN }\end{array}$} \\
\hline Parameters & Values \\
\hline$\lambda_{\max }$ & $422 \mathrm{~nm}$ \\
\hline Beer's law limit & $4-24 \mu \mathrm{g} / \mathrm{mL}$ \\
\hline Molar absorptivity $(\varepsilon)$ & $1.2971 \times 10^{4} \mathrm{~L} \mathrm{~mol}^{-1} \mathrm{~cm}^{-1}$ \\
\hline Sandell's sensitivity & $0.03194 \mu \mathrm{g} \mathrm{cm}^{-2} / 0.001$ abs unit \\
\hline Regression equation & $A=a x+b$ \\
\hline Slope (a) & 0.0472 \\
\hline Intercept (b) & -0.1622 \\
\hline Standard error on slope & 0.0065 \\
\hline Standard error on intercept & 0.0100 \\
\hline Correlation co-efficient (r) & 0.9987 \\
\hline
\end{tabular}

Limit of detection and limit of quantitation: The limit of detection as well as limit of quantitation of the method was established using the formula: $\mathrm{LOD}$ or $\mathrm{LOQ}=\kappa \mathrm{SD}$ a/b, where $\kappa=3$ for LOD and 10 for LOQ, SD is the standard deviation with intercept (a) and slope (b). The LOD and LOQ were 0.0045 and $0.0015 \mu \mathrm{g} \mathrm{mL^{-1 }}$ respectively. The low values indicate the high sensitivity of the proposed method and are comparable with that of the reported method ${ }^{23}$.

Application of the proposed method: The method was applied to the analysis of the bulk drug and the mean recovery value was found to be $99.88 \pm 0.57 \%$. It is evident from the aforementioned results that the proposed method gave satisfactory results for determination of escitalopram oxalate in bulk. For the application of the proposed method to formulation the procured tablets were subjected to the analysis for their contents of escitalopram oxalate by the proposed method and reported method ${ }^{23}$. The assay result for the marketed formulation for the proposed and reported extractive colourimetric method was found to be 100.01 and $99.97 \%$ respectively to that of label claim. This result was compared by statistical analysis with respect to student t- and F-test. No significant differences were found between the calculated and theoretical values of $t$ - and $F$-tests at $95 \%$ confidence level which prove that the present method is comparable with that of reference method (Table-2).

Precision of the method (repeatability): Intraday precision was determined from results obtained from six fold replicate analysis of sample on the same day. Interday precision was established from the results of the same sample examined on five successive days. The results obtained are given in Table-3. The percentage relative standard deviation (RSD \%) is low of about 0.798 and 0.971 for inter, intraday precision respectively, evidencing repeatability (precision) of the method.

Accuracy of the method (reproducibility): This was attained by recovery studies by spiking a known quantity of
ABLE-2

OF ASSAY

\begin{tabular}{cccc}
\multicolumn{2}{c}{$\operatorname{RSD}^{\mathrm{a}}(\%)$} & Confidence & \\
Proposed & Reported & -test $^{\mathrm{b}}$ & $F$-test \\
0.79 & 0.98 & 1.2 & 2.4
\end{tabular}

\begin{tabular}{ccccc} 
& \multicolumn{5}{c}{ TABLE-3 } \\
& \multicolumn{4}{c}{ Precision } \\
\hline & \multicolumn{4}{c}{ Intraday } \\
\cline { 2 - 5 } Conc. & \multicolumn{2}{c}{ Interday } & Amount \\
found & RSD $^{\mathrm{a}}$ \\
\cline { 2 - 5 } & $\begin{array}{c}\text { Amount } \\
\text { found } \\
(\mu \mathrm{g} / \mathrm{mL})^{\mathrm{a}}\end{array}$ & $\begin{array}{c}\mathrm{RSD}^{\mathrm{a}} \\
(\%)\end{array}$ & $\begin{array}{c}(\mu \mathrm{g} / \mathrm{mL})^{\mathrm{a}} \\
(\%)\end{array}$ \\
\hline 10 & 10.95 & 0.798 & 10.87 & 0.971 \\
\hline${ }^{\mathrm{a}}$ Mean of six determinations.
\end{tabular}

standard drug to the pre-analyzed sample and the estimation was carried out by the proposed analysis procedure. The results of recovery studies are given in Table- 4 . The mean RSD \% determined at three levels were $0.88-0.98 \%$, which were within the acceptance limit for accuracy of $<2 \%$ RSD proving the good accuracy of the purposed method.

\begin{tabular}{cccccc}
\multicolumn{7}{c}{ TABLE-4 } \\
\hline $\begin{array}{c}\text { Conc. } \\
(\mu \mathrm{g} / \mathrm{mL})\end{array}$ & $\begin{array}{c}\text { Spike } \\
\text { level } \\
(\%)\end{array}$ & $\begin{array}{c}\text { Amount } \\
\text { added } \\
(\mu \mathrm{g} / \mathrm{mL})\end{array}$ & $\begin{array}{c}\text { Amount } \\
\text { recovered } \\
\left(\mu \mathrm{g} / \mathrm{mL}^{\mathrm{a}}\right)\end{array}$ & $\begin{array}{c}\text { Recovery }^{\mathrm{a}} \\
(\%)\end{array}$ & $\begin{array}{c}\mathrm{RSD}^{\mathrm{a}} \\
(\%)\end{array}$ \\
\hline \multirow{2}{*}{10} & 75 & 9 & 9.01 & 100.1 & 0.98 \\
& 100 & 12 & 11.98 & 99.83 & 0.88 \\
& 125 & 15 & 14.99 & 99.93 & 0.97 \\
\hline
\end{tabular}

${ }^{a}$ Mean of five determinations.

Study on methyl orange concentration and quantity: The effect of the methyl orange was studied by measuring the absorbance of solutions containing escitalopram oxalate (10 $\mu \mathrm{g} / \mathrm{mL}$ ) and $0.5 \mathrm{~mL}$ of methyl orange solution at various concentration $(0.025-0.15 \% \mathrm{wt} / \mathrm{v})$. The results are portrayed in Fig. 4(a). As methyl orange concentration of $0.05 \% \mathrm{w} / \mathrm{v}$ gave a maximum absorbance, it was chosen as suitable for complexation. The effect of methyl orange quantity was studied by varying the volume of the dye added $(0.2-1.2 \mathrm{~mL})$ by maintaining the dye concentration of $0.05 \% \mathrm{wt} / \mathrm{v}$ and drug concentration of $10 \mu \mathrm{g} \mathrm{mL}^{-1}$ Fig. 4(b). From the results it was established that $0.05 \mathrm{~mL}$ of $0.05 \% \mathrm{wt} / \mathrm{v}$ methyl orange is sufficient to make complex with maximum absorbance. Volumes of above $0.05 \mathrm{~mL}$ reagent had no marked effect on the chromogen formation.

Study of interference and placebo study: Studies on interference by common excipients that might be added during formulations were carried by mixing known amount of escitalopram oxalate $(60 \mathrm{mg})$ with specified amounts of the common excipients listed in the Table- 5 and the recovery were calculated $^{21}$. The results are presented in Table-5. The used excipients do not cause any interference in the estimation of the drug. Likewise the mixture of above excipients was prepared without the drug (placebo) and the procedure was followed. Absence of colour in the extract revealed the selectivity of the present method for the analyte of interest. 

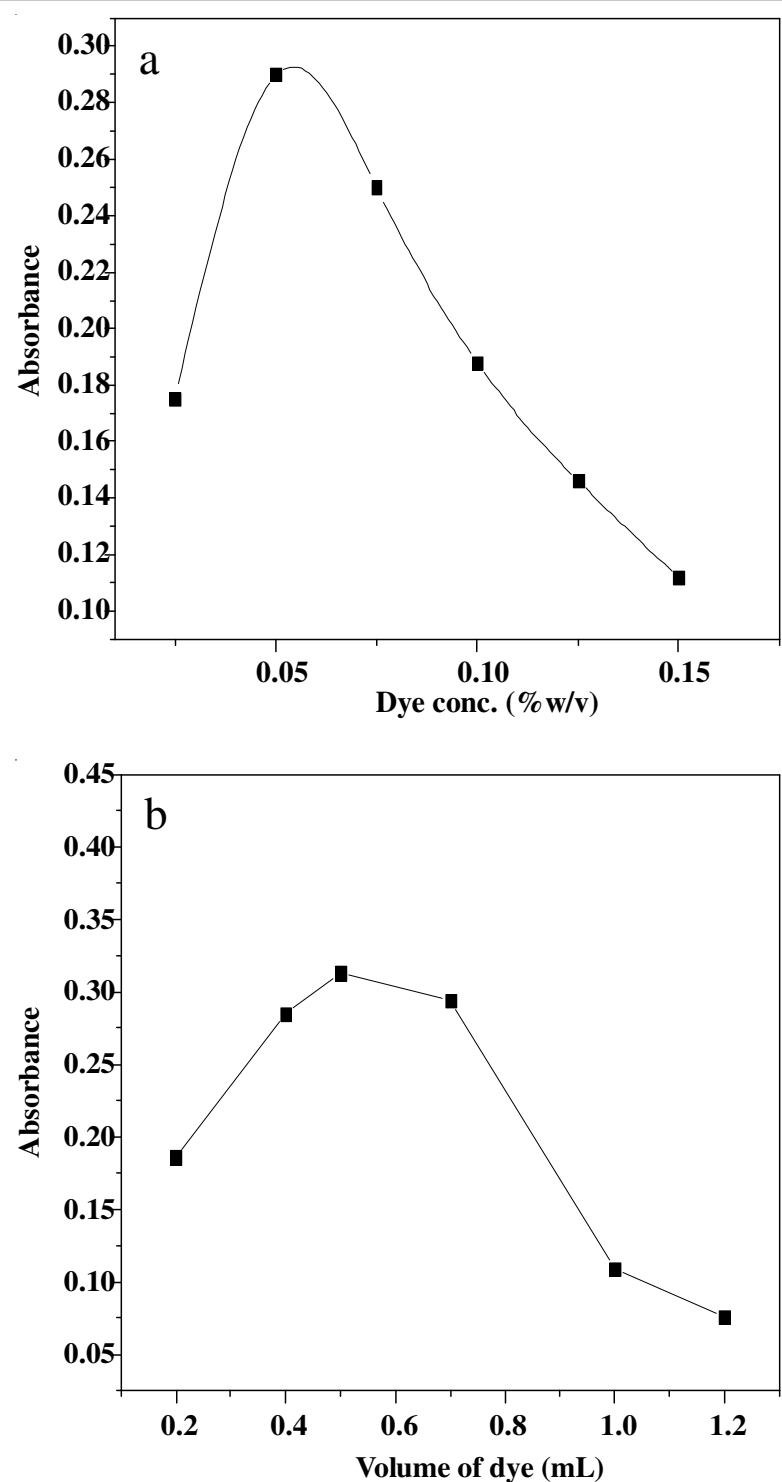

Fig. 4. (a) Effect of methyl orange concentration (b) Effect of methyl orange quantity

\begin{tabular}{cc}
\multicolumn{2}{c}{ TABLE-5 } \\
\hline \multicolumn{2}{|c}{ STUDY OF INTERFERENCE OF EXCIPIENTS } \\
\hline Excipients used $(10 \mathrm{mg})^{\mathrm{a}}$ & Recovery $(\%)( \pm \mathrm{SD})^{\mathrm{b}}$ \\
\hline Lactose & $98.99 \pm 0.381$ \\
Starch & $99.85 \pm 0.695$ \\
Talc & $99.98 \pm 0.545$ \\
\hline${ }^{\mathrm{a}}$ Quantity of excipients added per 60 mg of escitalopram oxalate \\
${ }^{\mathrm{b}}$ Mean of five determinations
\end{tabular}

Bench top stability of chromogen: To study the stability of chromogen, specified quantity of stock was mixed with above standardized quantity of methyl orange and kept aside for reaction and extracted with chloroform. Then the absorbance of the chromogen from the time of extraction (considered as $0 \mathrm{~min}$ ) to various time interval was determined and the results are plotted against time vs. absorbance (Fig. 5). The plot shows that the chromogen was stable more than $3.5 \mathrm{~h}$.

Robustness and ruggedness: Robustness (study of effect of deliberate change) was established by estimating the amount of escitalopram oxalate oxalate in tablet by making slight changes in wavelength of estimation and dye's concentration. The results obtained were within the suggested limits for $\%$ RSD $(<2 \%$ ) (Table-6). Ruggedness was established by determining escitalopram oxalate in the tablet formulation using two different spectrophotometer Shimadzu UV mini-1240 (system I) and SCINCO, Neosys-2000 DRS-UV provided with liquid sample analysis port (system II) and two different analysts (I and II). The results obtained were within the recommended \% RSD limit $(<2 \%)$.

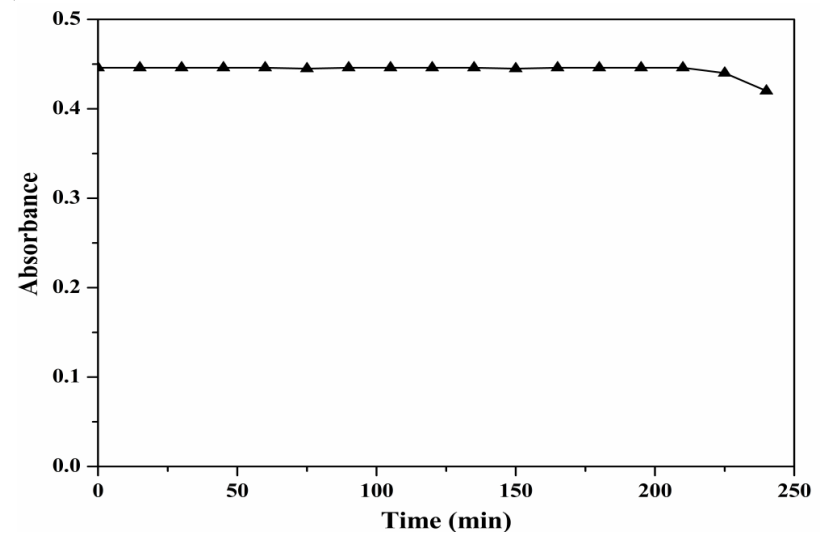

Fig. 5. Stability of escitalopram oxalate-methyl orange ion-pair complex

\section{Conclusion}

The proposed ion-pair extractive colourimetric estimation of escitalopram oxalate in bulk and in formulation is more sensitive, specific (selective), rapid and cost effective. The highest $\%$ recovery of the method proved that the present method was more accurate and comparable with that of reference method. The method is more selective for the drug which was proved from the interference studies with excipients such as lactose, starch and talc as it resulted with low \% RSD. As the proposed method makes use of simple reagent, it can be easily affordable by all analytical laboratories. Further the method doesn't use any buffer which reduces the cost of method. Hence, it is concluded that the developed method is suitable for routine determination of escitalopram oxalate in its formulations in terms of its complete validation.

\section{ACKNOWLEDGEMENTS}

The authors acknowledged the financial support by grants from Korea CCS R \& D centre, funded by the Ministry of Education, Science and Technology of the Korean Government.

\begin{tabular}{|c|c|c|c|c|c|c|c|}
\hline \multicolumn{8}{|c|}{$\begin{array}{c}\text { TABLE-6 } \\
\text { RESULTS OF ROBUSTNESS AND RUGGEDNESS }\end{array}$} \\
\hline \multicolumn{4}{|c|}{ Robustness } & \multicolumn{4}{|c|}{ Ruggedness } \\
\hline Wave length (nm) & $\mathrm{RSD}^{*}(\%)$ & MO Conc. $(\% \mathrm{w} / \mathrm{v})$ & RSD* $(\%)$ & Analyst & $\mathrm{RSD}^{*}(\%)$ & System & $\mathrm{RSD}^{*}(\%)$ \\
\hline 419 & 0.342 & 0.09 & 0.546 & I & 0.125 & I & 0.156 \\
\hline 421 & 0.421 & 0.11 & 0.798 & II & 0.752 & II & 0.963 \\
\hline
\end{tabular}




\section{REFERENCES}

1. Escitalopram oxalate. http://www.rxlist.com/cgi/generic/ lexapro.htm (Date accessed 03/01/2012).

2. W.J. Burke and C.J. Kratochvil, Prim. Care Comp. J. Clin. Psychiatry, 4, 20 (2002).

3. W.J. Burke, I. Gergel and A. Bose, J. Clin. Psychiatry, 63, 331 (2002).

4. V.Y. Yevtushenko, A.I. Belous, Y.G. Yevtushenko, S.E. Gusinin, O.J. Buzik and T.V. Agibalova, Clin. Ther, 29, 2319 (2007).

5. S. Schreiber and C.G. Pick, Eur. Neuropsychopharmacol., 16, 464 (2006).

6. M.M. Gutierrez, J. Rosenberg and W. Abramowitz, Clin. Ther, 25, 1200 (2003).

7. C. Sánchez, P.B. Bergqvist, L.T. Brennum, S. Gupta, S. Hogg, A. Larsen and O. Wiborg, Psychopharmacology, 167, 353 (2003).

8. S. Budavari, The Merck Index, an Encyclopedia of Chemicals, Drugs and Biologicals. Edn. 14 ${ }^{\text {th }}$, Merck and Co. Inc., Whitehouse Station, NJ (2001).

9. S.S. Singh, H. Shah, S. Gupta, M. Jain, K. Sharma, P. Thakkar and R. Shah, J. Chromatogr. B., 811, 209 (2004).

10. B. Raman, B.A. Sharma, P.D. Ghugare, S. Nandavadekar, D. Singh, P.K. Karmuse and A. Kumar, J. Pharm. Biomed. Anal., 53, 895 (2010).

11. N. Johannesson and J. Bergquist, J. Pharm. Biomed. Sci., 43, 1045 (2007).

12. C. Greiner, C. Hiemke, W. Bader and E. Haen, J. Chromatogr. B, 848, 391 (2007).

13. M. Kosel, C.B. Eap, M. Amey and P. Baumann, J. Chromatogr. B., 719, 234 (1998).
14. S. Andersen, T.G. Halvorsen, S. Pedersen-Bjergaard, K.E. Rasmussen, L. Tanum and H. Refsum, J. Pharm. Biomed. Anal., 33, 263 (2003).

15. T. Samanta, S. Dey, H.B. Samal, D.B. Kumar, D.L. Mohanty and K. Bhar, Int. J. Chem. Res., 2, 11 (2011).

16. A. Suneetha and B.S. Sundar, Int. J. Pharm. Biol. Sci., 2, 140 (2011).

17. N. Dhavale, S. Gandhi, S. Sabnis and K. Bothara, Chromatographia, 67, 487 (2008).

18. Y. Shete, N. Pimpodkar, N.S. Mahajan, Y.V. Pore, R.L. Jadhav and B.S. Kuchekar, Int. J. Chem. Sci., 7, 235 (2009).

19. S. Sharma, H. Rajpurohit, C. Sonwal, A. Bhandari, V.R. Choudhary and T. Jainm J. Young Pharm., 2, 420 (2010).

20. S.A. Al-Tamimi, F.A. Aly and O.M. Al-Otaibi, Asian J. Chem., 24, 5515 (2012).

21. R.B. Kakde and D.D. Satone, Indian J. Pharm. Sci., 71, 702 (2009).

22. B.G. Chaudhari and H.R. Parmar, Int. J. Pharm. Qual. Assur., 2, 9 (2010).

23. T. Vetrichelvan, K. Arul, M. Sumithra and B. Umadevi, Indian J. Pharm. Sci., 72, 269 (2010)

24. P. Job, in ed.: B. Oliner, Advanced Physico Chemical Experiments, Edinburgh, UK, p. 54 (1964).

25. The United States Pharmacopeia, The National Formulary 19, US Pharmacopeial Convention Inc., Rockville, MD (2000).

26. ICH, Validation of Analytical Procedures: Text and Methodology Q2 (R1), International Conference on Harmonization, Geneva, November (1996). 